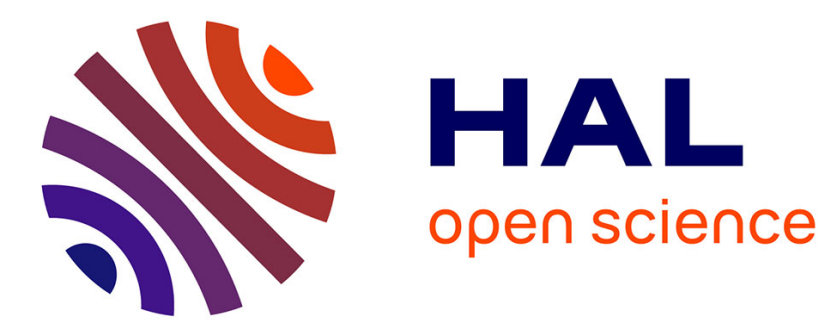

\title{
VCSEL collimation using self-aligned integrated polymer microlenses
}

Christophe Levallois, Véronique Bardinal, Corinne Vergnenegre, Thierry

Leichle, Thierry Camps, Emmanuelle Daran, Jean-Baptiste Doucet

\section{To cite this version:}

Christophe Levallois, Véronique Bardinal, Corinne Vergnenegre, Thierry Leichle, Thierry Camps, et al. VCSEL collimation using self-aligned integrated polymer microlenses. Photonics Europe, Apr 2008, Strasbourg, France. pp.69920W, 10.1117/12.780545 . hal-00489082

\section{HAL Id: hal-00489082 https://hal.science/hal-00489082}

Submitted on 3 Jun 2010

HAL is a multi-disciplinary open access archive for the deposit and dissemination of scientific research documents, whether they are published or not. The documents may come from teaching and research institutions in France or abroad, or from public or private research centers.
L'archive ouverte pluridisciplinaire HAL, est destinée au dépôt et à la diffusion de documents scientifiques de niveau recherche, publiés ou non, émanant des établissements d'enseignement et de recherche français ou étrangers, des laboratoires publics ou privés. 


\title{
VCSEL collimation using self-aligned integrated polymer microlenses
}

\author{
Christophe Levallois ${ }^{\mathrm{a}, \mathrm{b}}$, Véronique Bardinal ${ }^{\mathrm{a}^{*}}$, Corinne Vergnenègre ${ }^{\mathrm{a}}$, Thierry Leïchlé ${ }^{\mathrm{a}}$, Thierry \\ Camps $^{\mathrm{a}}$, Emmanuelle Daran ${ }^{\mathrm{a}}$, and Jean-Baptiste Doucet ${ }^{\mathrm{a}}$ \\ a) LAAS-CNRS, Université de Toulouse, 7, Avenue du Colonel Roche F-31077 Toulouse \\ Cedex 04, France ; \\ b) now at UMR-FOTON CNRS 6082, INSA de Rennes, 20 Avenue des Buttes de Coësmes, CS \\ 14315 - 35043 Rennes Cedex, France
}

\begin{abstract}
We report on the design and fabrication of polymer microlenses fabricated on patterned SU-8 layers in view of integrating microlenses on VCSEL arrays for laser beam shaping. For a standard top-emitting VCSEL, the lens has to be fabricated on a thick intermediate layer (pedestal) whose optimal thickness can be modelled as a function of the initial and of the aimed optical properties of the VCSEL beam. In this work, pedestals are fabricated with SU-8, which is a negative-tone photoresist transparent at the lasing wavelength. Lens deposition is realized using a robotized silicon microcantilever spotter technique after a simple SU-8 photolithography step in order to define high aspect ratio cylindrical pedestals with wide range diameters $[30-140 \mu \mathrm{m}]$. The effect of pedestal diameter on the final contact angle and curvature radius has been investigated using non contact optical profilometry and scanning electron microscopy. We show that this technique leads to a complete delimitation of the polymer droplets and to a better control of the final lens size. Moreover, lens positioning is fully ensured by the self-alignment of the droplet with the pillar center and consequently with the VCSEL source, and allows for meeting the stringent requirements on alignments.
\end{abstract}

Keywords: VCSEL, micro-optics, polymer, microcantilevers, SU-8.

\section{INTRODUCTION}

Thanks to their low power consumption and their highly parallel operation, VCSEL (Vertical Cavity Surface-Emitting Lasers) have become extremely attractive light sources for many applications, ranging from optical communications, instrumentation and sensing. However, despite a limited far-field beam divergence, these sources have often to be associated with micro-optical components to enhance their performances or to improve their integration in photonic systems. Most of the requirements concern beam collimation (beam divergence $1^{\circ}$ ) or beam focusing with fixed values of waist around few tens of microns and working distances comprised between $10 \mu \mathrm{m}$ to $1 \mathrm{~mm}$.

The hybrid assembly of a microlens array above a VCSEL array ${ }^{1}$ is the most common way to solve this problem. However this approach implies a tricky hybridation step on active devices to meet the requirements on the vertical and lateral positionings of the microlenses relatively to the source placed above. Moreover this assembly can not be achieved collectively onto a whole wafer. Consequently, microlenses monolithically integrated on the VCSEL surface are often preferable. Such an integrated optical system allows for reduction in packaging costs and makes VCSEL integration in microsystems easier. Moreover it allows to precisely optimize the lens geometrical parameters taking into account the real numerical aperture of the source - VCSELs being testable under probes before dicing and assembly steps - and according to the aimed application: collimation or focusing... leading to a kind of "custom-made" microlens.

Integrated lenses can be defined on either of the two faces of the VCSEL wafer. However, lenses defined by etching the back surface of the wafer are only usable for long-wavelength bottom-emitting VCSELs because of GaAs substrate optical absorption ${ }^{2,3}$ For a more general approach, microlenses have to be defined on the emitting surface of the device

\footnotetext{
*bardinal@laas.fr; phone 33(0)5 61337836; fax 33(0)5 61336208; laas.fr
} 
and a thick intermediate transparent layer, named pedestal in the following, has first to be deposited ${ }^{4,5}$. We report here on the collective fabrication of self-aligned polymer microlenses arrays deposited on SU-8 pedestals using a polymer robotized silicon-cantilever-based microsystem. As presented in the next section, microlenses have been first modelled to optimize their geometrical parameters. Results of lens design as well as the influence of the fabrication parameters fluctuations on the divergence will be detailed. Technological steps to achieve high optical quality polymer lenses will be described in Section 3. Finally, results on droplets deposition on SU-8 cylindrical pedestals leading to a self-alignment of the lenses relatively to VCSEL sources will be presented.

\section{DESIGN OF INTEGRATED MICROLENSES FOR VCSEL COLLIMATION}

The deposited microlenses are assumed to modify the divergent Gaussian beam emitted by the VCSEL into a well controlled laser beam, whose divergence is as low as possible. To optimize this divergence, we used the optical simulation tool Zemax. The simulation implements two layers between the VCSEL laser source and the free air propagation space, as showed in the Fig.1: a thick pedestal and the polymer-made lens meniscus. The VCSEL source has a $1.3 \mu \mathrm{m}$ waist size, corresponding to a $14^{\circ} \mathrm{FWHM}$ divergence, which is a typical value measured on our single-mode oxide-confined devices. It emits light at $850 \mathrm{~nm}$ and the VCSEL array presents a source pitch equal to $250 \mu \mathrm{m}$. The pedestal material is composed of SU-8 photoresist. The simulation and optimization focused on the lens geometry as far as the pedestal height, the association both of theses parameters leading to the required divergence.

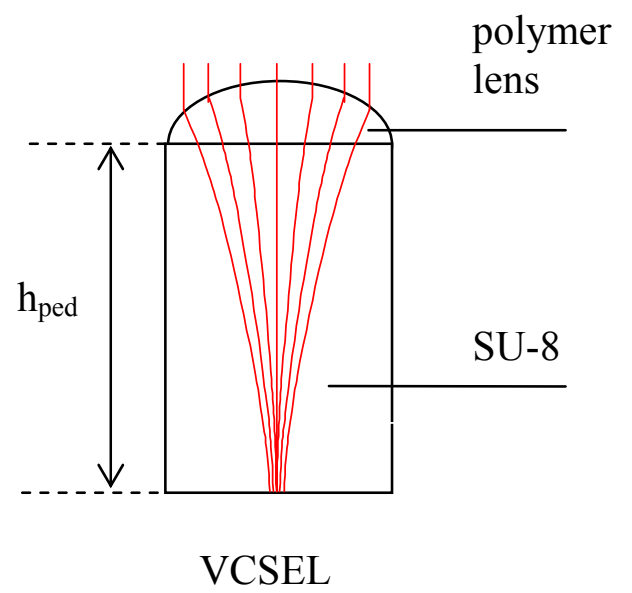

Fig.1: Description and notation of the system pedestal + lens

The notations used for dimensioning the lens are given in Fig.2.

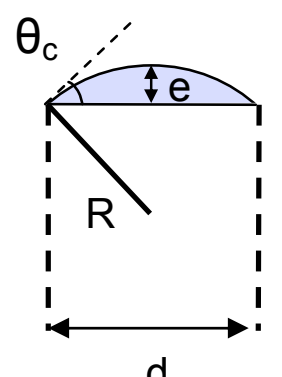

Fig. 2: Scheme and notation of the simulated lens

$\mathrm{R}$ is the radius of curvature of the lens, $\mathrm{e}$ its thickness and $\mathrm{d}$ its diameter. $\theta_{\mathrm{c}}$ is the contact angle of the lens. We have the following relations between these different parameters: 


$$
\mathrm{R}=\frac{1}{2 \mathrm{e}}\left(\frac{\mathrm{d}^{2}}{4}+\mathrm{e}^{2}\right) ; \theta_{\mathrm{c}}=\arcsin \left(\frac{\mathrm{d}}{2 \mathrm{R}}\right) \text { and } \mathrm{e}=\mathrm{R}\left(1-\cos \theta_{\mathrm{c}}\right)
$$

The study of the source divergence has been carried out as a function of the lens diameter and of the pedestal height, for different lens diameters.

The results are shown in Fig.1 and Fig.2 and point out that a minimum divergence of $1^{\circ}$ (corresponding to a reduction of can be reached over a wide range of the structural parameters combination. It has to be noted that the system is more tolerant when the lens diameter increases, as it implies an increase of the pedestal height too.

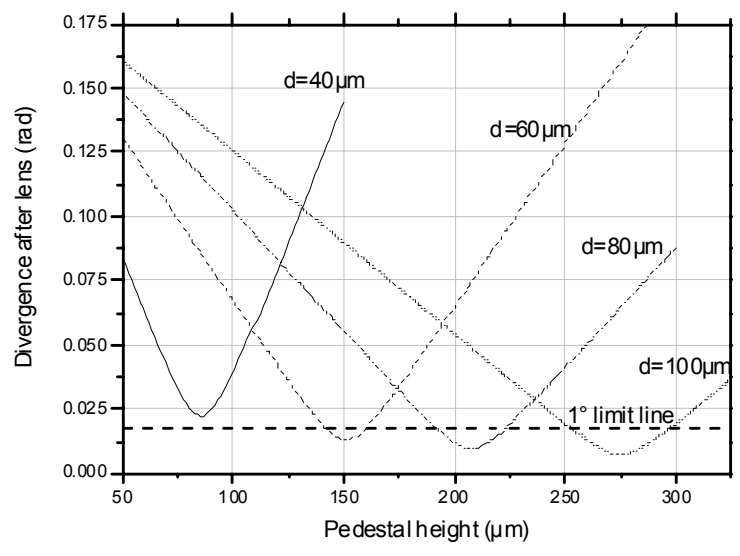

Fig.1. Divergence as a function of pedestal height - Contact angle $=40^{\circ}$

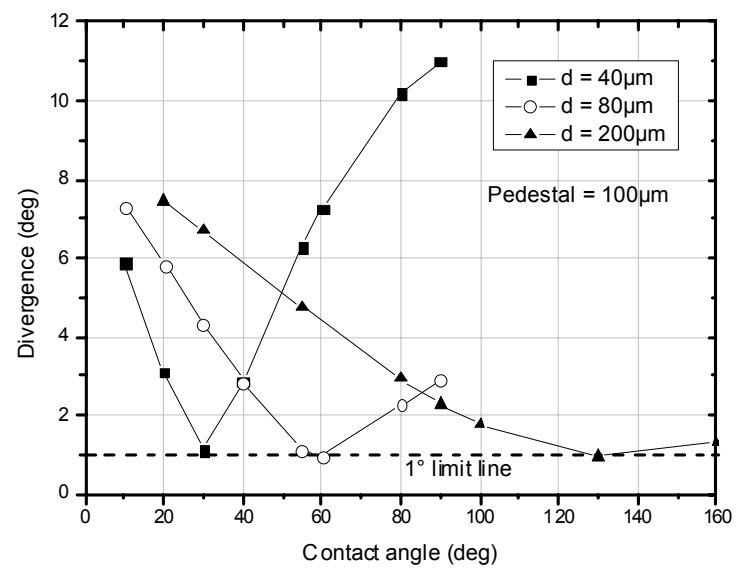

Fig. 2. Divergence as a function of drop contact angle Pedestal height $=100 \mu \mathrm{m}$

Nevertheless, these results have to be related to the technological facilities and the realization parameters. Corresponding polymer volumes to drop have been also calculated ${ }^{16}$ and are comprised in a range from few picoliters to few hundred picoliters. This implies the use of a deposition technique suitable to this volume range.

\section{MICROLENS FABRICATION TECHNOLOGY}

The fabrication of microlens arrays has been a key subject in micro-optics for more than 15 years ${ }^{7,8}$. Nowadays, most of the studies concern polymer microlenses because of their low cost and their convenience. Many fabrication techniques are possible: thermal photoresist reflow ${ }^{9}$, laser ablation ${ }^{10}$, direct writing by electronic beam or laser beam ${ }^{11}$, deep lithography by protons ${ }^{11}$, LIGA process ${ }^{12}$, photo-polymerization ${ }^{13}$, ink-jet printing ${ }^{5}, \mathrm{UV}$-imprint ${ }^{6}, \ldots$ However, many of these techniques are not consistent with a device post-processing. Consequently, only few demonstrations of monolithic integration of microlenses on VCSELs arrays have been done up to now using ink-jet, dispensing methods and UVmolding techniques. To our knowledge, the most advanced results have been obtained with dispensing methods allowing a localized polymer deposition such as micro-jet printing ${ }^{15}$ as they open the possibility to adjust the size and the shape of the lenses during the deposition process. Because the lens formation originates from surface tension of the liquid polymer droplet, these methods lead to good surface morphology and thus to high optical quality.

We have recently proposed an original approach that can lead to similar results and which is based on the deposition of low viscosity polymer droplets using an automatized array of silicon microcantilevers. This microsystem-based spotting tool, consisting of a cantilever array fixed on a three-stage automated spotter, was initially developed for picoliter biological sample deposition ${ }^{16}$. The microcantilever array is spatially moved owing to a computer-controlled three-axis translation stage (Fig.5). Liquid droplet deposition is achieved by putting the cantilevers in contact with the substrate surface. The polymer used in this study is a home-made thermocurable polymer with a very low viscosity [15]. After deposition, droplets are in situ polymerised at $120^{\circ} \mathrm{C}$ owing to the use of a heating plate. 
The ability of this technique to deposit hemispherical lenses in the size range required for integration on VCSEL has been recently experimentally demonstrated ${ }^{17}$. As seen in Fig.6 and Fig.7, the droplet diameter can be tuned by increasing the contact time. For contact times higher than $30 \mathrm{~s}$, lens diameter does not increase anymore and the maximum value achievable depends of the size of the fluidic channel of the microcantilever, of the surface tension of the liquid polymer and of the wettability of the surface. In our conditions (channel size: $5 \mu \mathrm{m}$, epoxy-siloxane polymer and SU-8 surface), this value is equal to $130 \mu \mathrm{m}$. Corresponding focal lengths evolve linearly with the diameter and are in the range [60$180 \mu \mathrm{m}$ ] (Fig.8). A detailed study of the properties of such microlenses can be found in a previous published work ${ }^{18}$.

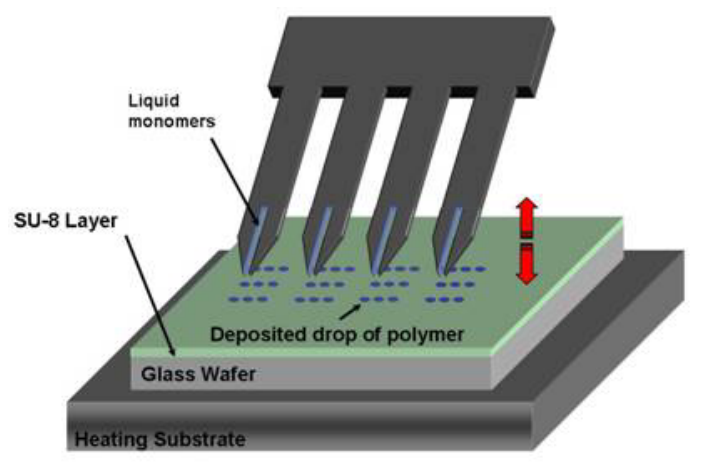

Fig.5. Principle of polymer lens deposition using a robotized silicon-cantilever microspotter

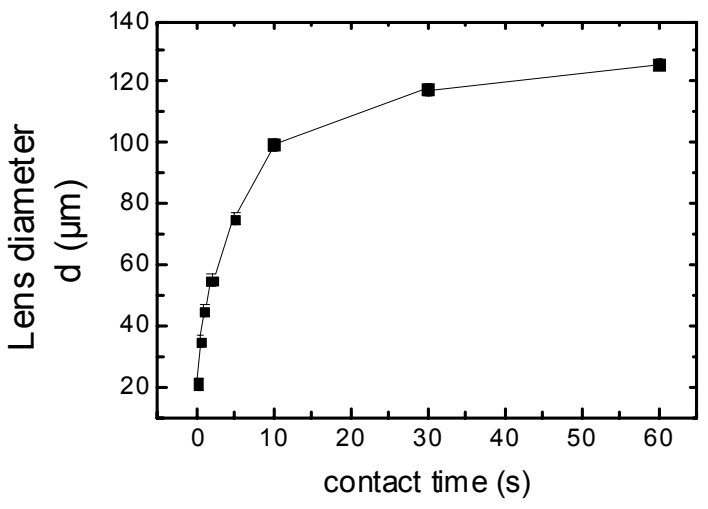

Fig.7. Evolution of lens diameter as a function of contact time

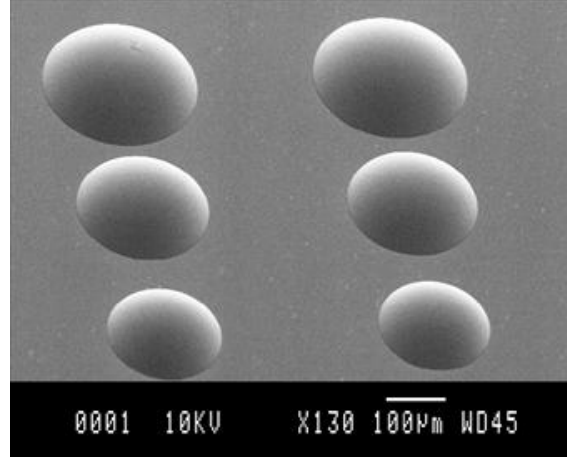

Fig.6. SEM (Scanning Electron Microscopy) image of microlenses obtained for three different contact times using the microspotter system

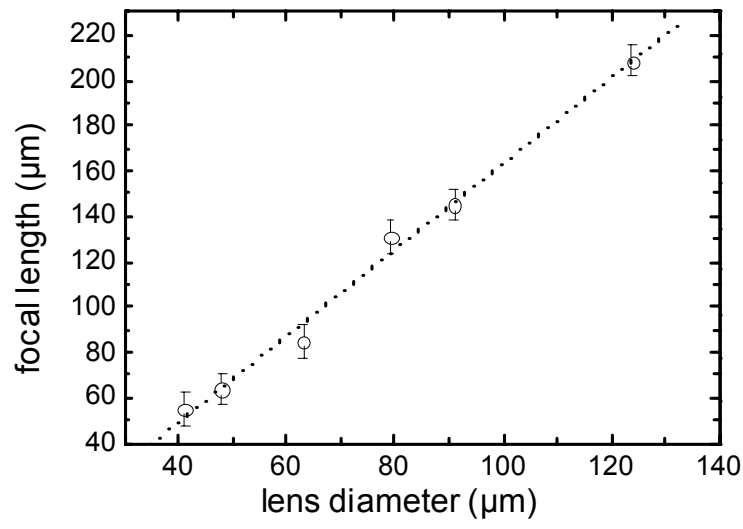

Fig.8. Evolution of focal length as a function of lens diameter

\section{SU-8 PATTERN FABRICATION AND SELF-CENTERING PROPERTIES}

As mentionned previously, the realization of a thick intermediate layer is necessary to integrate microlenses on VCSEL for beam collimation. Localized pedestals have to be defined on the VCSEL wafer following the laser device fabrication, to allow microlenses deposition on devices and to keep a free electrical access for each device.

These pedestals are composed of SU-8, a negative-tone photoresist often used for MEMS or microfluidic applications (SU-8 3050 - MicroChem Corporation). The SU-8 photoresist is spin-coated, and a simple photolithography step is then realized to define pedestals. SU-8 has been first deposited on silicon and glass wafers in order to check our ability to deposit microlenses on patterned layers whose thickness is close to $100 \mu \mathrm{m}$. Such a thickness is a trade-off between an efficient reduction of the initial beam divergence and facilities to obtain uniform SU-8 layers.

Polymer microlens deposition has been first tested on band-shaped pedestals arrray comprising large strips. Microlenses deposited on such strips are illustrated in Fig. 9. The polymer behaviour is found to be similar to the one encountered in the case of flat SU-8 layers: droplets dimensions are controlled by the contact time of the cantilevers on the surface. For 
these kind of patterned surfaces, the droplets dimensions are indeed much lower than the strips dimensions $(300 \mu \mathrm{m} x$ $1000 \mu \mathrm{m})$. Consequently, the droplets are not affected during the deposition by the strips boundaries.

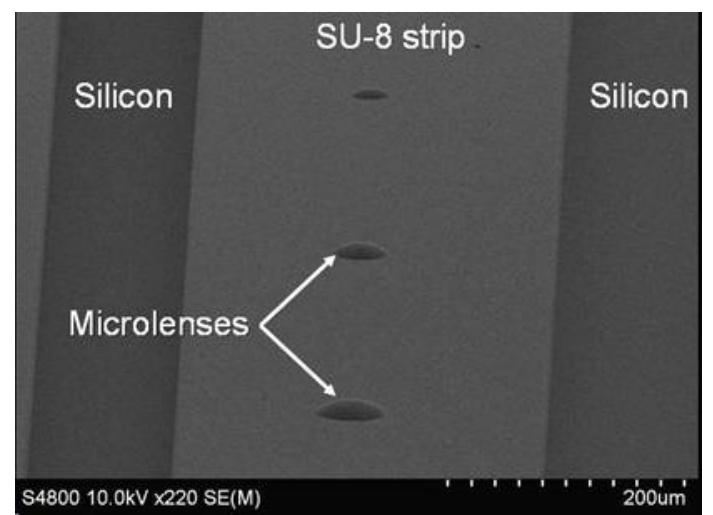

Fig. 9. SEM image of microlenses deposited on a strip-shaped SU-8 pedestal

As it can be seen in Fig.9, the microlenses are aligned with to the strip center. However, although cantilevers can be moved with a micrometric relative resolution, the positioning accuracy of the microlenses with the VCSEL source located $100 \mu \mathrm{m}$ below is found to be not better than $5 \mu \mathrm{m}$ due to the limitations of the optical visualisation system used. Moroever, whatever the highest accuracy of the positioning achievable using a localized dispending technique, it is better to set the lens position with a photolithographic step to meet the stringent requirements on lens/VCSEL alignment (accuracy $\pm 1 \mu \mathrm{m}$ ). This can be done by defining high aspect ratio cylindrical patterns (Fig.10) to localize polymer droplets $^{18}$. As illustrated in Fig.11, above a minimum value of deposited volume, lens positioning is fully ensured by the self-alignment of the droplet with the pillar center and consequently with the VCSEL source.

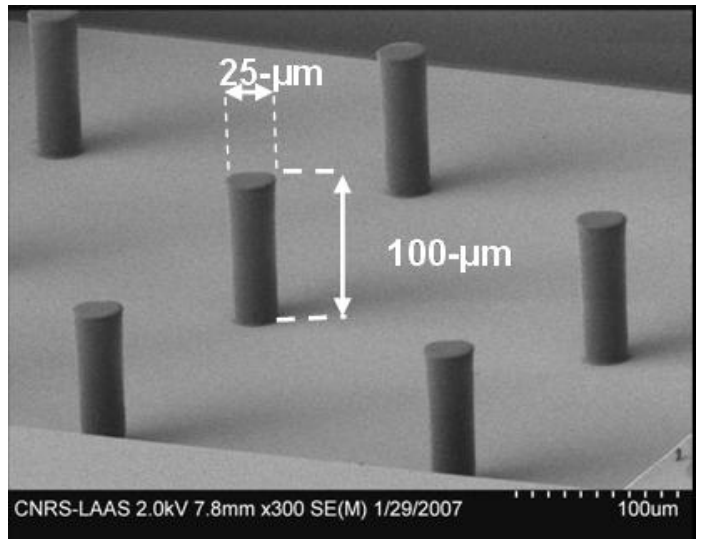

Fig. 10. SEM image of high aspect-ratio cylindrical SU-8 pedestals arrays.

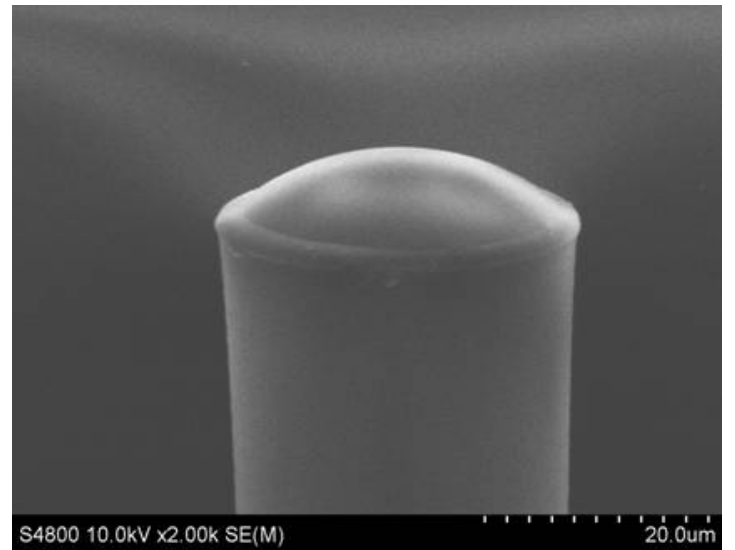

Fig. 11. SEM image of a microlens with a diameter of $30-\mu \mathrm{m}$ deposited on a cylindrical pedestal.

Non-contact optical profilometry characterizations have been carried out on microlenses deposited on cylindrical pedestals of various sizes (Fig. 12). For this study, high aspect ratio cylindrical pedestals have been fabricated in a wide

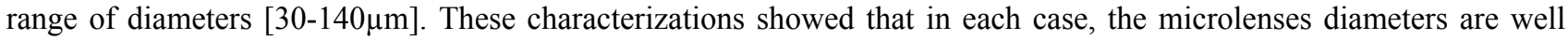
fixed by the pedestals perimeter. As a consequence, a better control is also obtained on the radius of curvature, and on the SAG of microlenses. These parameters are reported for different pedestals diameters in Fig. 13, for which all the deposited microlenses are found to be delimited by pedestal boundaries. For each size, the deposition of 12 successive identical droplets on 12 identical pedestals have been realized and characterized. Circular fits have been performed on the measured profiles. After a geometrical analysis, we can conclude that all microlenses have a spherical shape similar to the ones observed in the case of deposition on a plane surface. Moreover, as illustrated in Fig. 13, the curvature radii is totally set by the pedestal dimension and is comprised between $38-\mu \mathrm{m}$ for the smallest pedestal to $110-\mu \mathrm{m}$ for the largest. 
A similar behaviour is observed for the SAG of the lens. Moreover, we have measured a standard deviation of 5\% on these two parameters. These results show that the combination of our deposition technique with a single micro-patterning photolithography step of SU-8 leads to a complete delimitation of the microlens size as well as of its positionning.

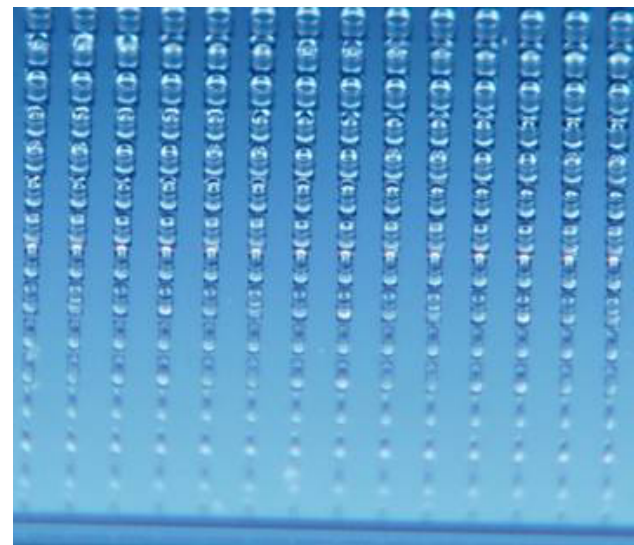

Fig. 12. Microscope image of an array of cylindrical pedestals of various diameters [30-140 $\mu \mathrm{m}]$ with microlenses deposited on their surfaces.

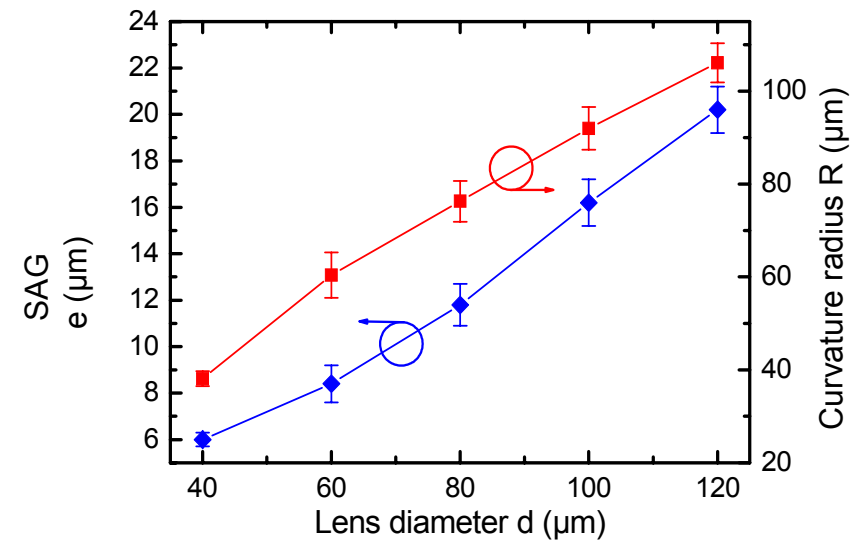

Fig. 13: Image of an array of cylindrical pedestals with microlenses deposited on their surfaces.

Fig.14 represents a schematic view of the fabricated laser devices including integrated lenses. The semiconductor laser diodes are standard top-emitting VCSEL designed for emission at $850 \mathrm{~nm}$.

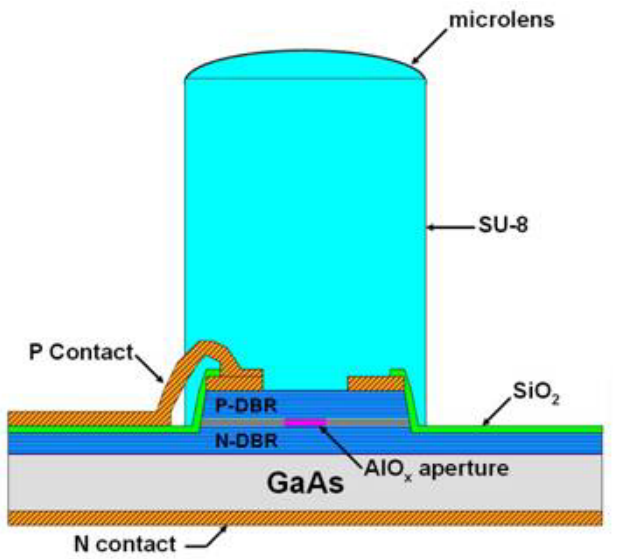

Fig. 14: Schematic view of the fabricated VCSEL with an integrated microlens 
$\mathrm{An} \mathrm{AuGe} / \mathrm{Ni} / \mathrm{Au}$ electrode is evaporated on the backside of the GaAs substrate to realize the p-type bottom contact. The p-type contact consists in a Ti/Au annular ring. These metallic layers are deposited before the mesa etching by ICP. Lateral electrical and optical confinements are provided by oxidizing an AlGaAs layer to form an oxide aperture with a diameter close to $4 \mu \mathrm{m}$. The surface is passivated with a $\mathrm{SiO}_{2}$ layer before the realization of a $1 \mu \mathrm{m}$-thickness air-bridge final metallization to ensure a good metal continuity on the side of the mesa. Final steps consist in pedestal fabrication and lens deposition. First far-fields measurements on such devices demonstrate that laser beam divergence is divided by a factor 5 without significant modification of laser performances.

\section{CONCLUSIONS}

In conclusion, a low-cost deposition technique based on a microcantilever-based spotter has been used to deposit microlenses on SU-8 patterned surfaces. Simulations have been performed demonstrating that the microlenses sizes achievable with this method are well suited for VCSEL beam application. In order to integrate such microlenses onto VCSEL devices, uniform thick SU-8 pedestals implementing different geometries and sizes have been fabricated and their influence on the deposited microlenses has been studied. We have shown that a cylindrical shape is the best suited to ensure a self-alignment of the polymer droplets on the top of the pedestal. It allows for an accurate positioning of the lens with the VCSEL sources by means of a single photolithography step, reducing thus strongly the requirements on the accuracy on the dispended volume. Finally, the application of this method to the monolithic integration of self-aligned polymer refractive microlenses on VCSEL has been realized and has led to a reduction by a factor 5 of the initial beam divergence.

\section{ACKOWLEDGEMENTS}

This work is supported by an internal project of the LAAS-CNRS laboratory. The authors wish to thank Chantal Fontaine, Jean-Bernard Pourciel and Liviu Nicu for fruitful discussions.

\section{REFERENCES}

[1] C.Vergnenègre, T.Camps, V.Bardinal, C.Bringer, C.Fontaine, A.Muñoz-Yagüe "Integrated optical detection subsystem for functional genomic analysis biosensor", Proceedings of SPIE, vol. 5969, Photonics Applications in Biosensing and Imaging, pp.596912.1-596912.10,(2005).

[2] K. Hedsten, J. Melin, J. Bengtsson, P. Modh, D. Karlén, B. Löfving, R. Nilsson, H. Rödjegård, K. Persson, P. Enoksson, F. Nikolajeff and G. Andersson "MEMS-based VCSEL beam steering using replicated polymer diffractive lens", Sensors and Actuators A: Physical Volume 142, Issue 1, pp 336-345, (2008).

[3] E. Strzelecka, D. Louderback, B. Thibeault, G. Thompson, K. Bertilsson, and L. Coldren, "Parallel Free-Space Optical Interconnect Based on Arrays of Vertical-Cavity Lasers and Detectors with Monolithic Microlenses ," Appl. Opt. 37, pp 2811-2821, (1998).

[4] Y. Fu "Integration of microdiffractive lens with continuous relief with vertical-cavity surface-emitting lasers using focused ion beam direct milling", IEEE Photonics Technology Letters, Vol. 13, Issue 5, pp 424-426, (2001).

[5] D.J. Hayes, M.E. Grove, D.B. Wallace, T.Chen, W.R. Cox, "Ink-jet printing in the manufacturing of electronics, photonics, and displays" Proceedings of SPIE, vol. 4809 Nanoscale Optics and Application, p.9499, (2002).

[6] A. Braueur, P. Dannberg, U.Zeitner, G. Mann, W. Karthe. "Application oriented complex polymer microoptics" Microsystem Technologies 9, Springer-Verlag p.304-307, (2003). 
[7] "Micro-Optics, Elements, systems and applications", Edited by Hans Peter Herzig, Taylor and Francis, (1997).

[8] H Ottevaere, R Cox, H P Herzig, T Miyashita, K Naessens, M Taghizadeh, R Völke, H J Woo and H Thienpont "Comparing glass and plastic refractive microlenses fabricated with different technologies" J. Opt. A: Pure Appl. Opt. 8, S407-S429, (2006).

[9] Z. Popovic, R. Sprague, and G. Connell, "Technique for monolithic fabrication of microlens arrays," Appl. Opt. 27, pp 1281-1284, (1988).

[10]K. Naessens, H. Ottevaere, R. Baets, P. Van Deale, H. Thienpont "Direct writing of microlenses in polycarbonate with excimer laser ablation" IEEE PTL Vol.6 Nº pp. 1112-1114, (1994).

[11] M. T. Gale, M. Rossi, J. Pederson, "Fabrication of continuous relief micro-optical elements by direct laser writing in photoresists", Opt. Eng., Vol. 33, n¹1, pp 3556-3566, (1994).

[12]H. Ottevaere, B. Volckaerts, J. Lamprecht, J. Schwider, A. Hermanne, I. Veretennicoff and H. Thienpont "Two dimensional plastic microlens arrays by deep lithography with protons : fabrication and characterization " J.Opt.A:Pure Appl.Opt. 4, pp S22-S28, (2002).

[13]P Ruther, B Gerlach, J Göttert, M Ilie, J Mohr, A Müller and C Oßmann "Fabrication and characterization of microlenses realized by a modified LIGA process" Pure Appl. Opt. 6 pp 643-653, (1997).

[14]C. Croutxé-Barghorn, O. Soppera, D.J. Lougnot, "Fabrication of microlenses by direct photo-induced crosslinkikng polymerization" Applied Surface Science, 168,pp.89-91, (2000).

[15]P. Belaubre, M.Guirardel , V.Leberre, J.B.Pourciel , C.Bergaud "Cantilever-based microsystem for contact and non-contact deposition of picoliter biological samples", Sensors \& Actuators A: Physical, Issues 1-3, Vol.110, pp.130-135, (2004).

[16] V.Bardinal, E.Daran, C.Vergnenègre, T.Leïchlé, Y.Ségui, T.Camps, J.B.Pourciel, V.Conédéra, L.GavinDjidina, M.Guirardel "Design and fabrication of polymer microlenses arrays for VCSELs using a cantileverbased microsystem", Proc. of SPIE. Micro-Optics, VCSELs, and Photonic Interconnects II: Fabrication, Packaging, and Integration, Vol.6185, p.618510, (2006).

[17] V.Bardinal, E.Daran, T.Leichlé, C.Vergnenègre, C.Levallois, T.Camps, V.Conedera, J.B.Doucet, F.Carcenac, H.Ottevaere, H.Thienpont «Fabrication and characterization of microlens arrays using a cantilever-based spotter » Optics Express Vol. 15, Issue 11, pp. 6900-6907, (2007).

[18] A. K. Nallani, T. Chen, D. J. Hayes, W-.S. Che, and J.-B. Lee "A Method for Improved VCSEL Packaging Using MEMS and Ink-Jet Technologies» Journal of Lightwave Technology, Vol. 24, Issue 3, pp. 1504, (2006). 